Discussion Paper No. 524

\title{
GROWTH OR STAGNATION: \\ ECONOMIC CONSEQUENCES OF \\ STATUS PREFERENCE
}

\author{
Yoshiyasu Ono
}

January 2001

The Institute of Social and Economic Research

Osaka University

6-1 Mihogaoka, Ibaraki, Osaka 567-0047, Japan 


\title{
Growth or Stagnation: \\ Economic Consequences of Status Preference
}

\author{
by \\ Yoshiyasu Ono \\ Osaka University
}

\begin{abstract}
Using a dynamic optimization model with status preference this paper shows that depending on the object of people's status preference an economy exhibits a completely opposite performance; permanent growth or persistent stagnation. If the object is a producible asset (viz. real capital), new employment is created and extra production is invested in capital, which generates permanent growth even under decreasing returns to capital. If it is an unproducible asset (viz. money), commodity demand is not created and deflation occurs. Full employment is never reached under nominal wage sluggishness although prices and wages continue to adjust.
\end{abstract}

Keywords: Status Preference, Long-Run Growth, Persistent Unemployment.

JEL Classifications: E12, E24, O41

Correspondence: Yoshiyasu Ono, The Institute of Social and Economic Research, Osaka University, 6-1, Mihogaoka, Ibaraki-shi, Osaka, 567-0047, Japan. e-mail: ono@iser.osaka-u.ac.jp

\footnotetext{
* The author is indebted to Ryo Horii, Shinsuke Ikeda, and Akihisa Shibata for their valuable comments.
} 


\section{Introduction}

"Why do the rich save so much?" (Carroll, 2000). It is naturally attributed to Veblen's status preference (1949) or Weber's capitalist spirit (1958). If people have a desire to be richer than others, they continue to save since others also accumulate wealth and hence they can never feel richer than others. Keynes (1972, p.326) states:

Now it is true that the needs of human beings may seem to be insatiable. But they fall into two classes - those needs which are absolute in the sense that we feel them whatever the situation of our fellow human beings may be, and those which are relative in the sense that we feel them only if their satisfaction lifts us above, makes us feel superior to, our fellows. Needs of the second class, those which satisfy the desire for superiority, may indeed be insatiable; for the higher the general level, the higher still they are.

If such status preference is directed toward a producible asset, such as real capital, new employment is created and extra production is invested in capital, which would generate permanent growth. However, if it is directed toward an unproducible asset, such as money and land, new employment is not created. Then, a shortage of demand would occur and deflation would last. Keynes (1936, p.235) also states:

Unemployment develops, that is to say, because people want the moon;- men cannot be employed when the object of desire (i.e. money) is something which cannot be produced and the demand for which cannot be readily choked off.

Using a dynamic optimization model with status preference, this paper exhibits such a sharp contrast between the status preference directed toward capital and that toward money or land.

Recently, the literature on status preference has been expanding. When analyzing long-run growth in the presence of status preference, most of them, e.g., Cole, Mailath and Postlewaite (1992), Fershtman, Murphy and Weiss (1996), Corneo and Jeanne (1997, 1999), Rauscher (1997), Zou (1995, 1998), and Futagami and Shibata (1998), assume constant returns to capital. Under this assumption long-run growth naturally occurs regardless of status preference, as is widely known in the literature of 
endogenous growth. When decreasing returns to capital are assumed, long-run growth does not occur and thus the effect of status preference on the absolute level of capital in the steady state is analyzed (Rauscher, 1997; Zou, 1998). However, Max Weber's original view is that the spirit of capitalism alone generates growth. In fact, Zou (1994) and Corneo and Jeanne (1995) show that in the presence of status preference directed toward real capital long-run growth can occur even under decreasing returns to capital.

This paper shows that in such an economy if people's status preference is directed toward an unproducible asset (viz. money) instead of real capital, deflation and stagnation occur as steady-state phenomena. Thus, whether status preference is directed toward a producible asset or an unproducible one leads to a quite opposite performance of an economy; namely, long-run growth or long-run stagnation.

The plan of this paper is as follows. Section 2 examines the dynamics of a nonmonetary economy where people's status preference is directed toward real capital. It is shown that there is a case where capital eternally grows on the unique equilibrium path even under decreasing returns to capital. This endogenous growth is purely supported by people's desire to climb up the ladder of social status.

Section 3 considers a monetary economy where people's status preference is directed toward money. It finds that an economy with weak status preference is most probably located in a state with persistent deflation. It also shows that no dynamic equilibrium path is supported if status preference is strong. In such a case, if nominal wage adjustment is sluggish, deflation and unemployment would occur. Section 4 examines this property and shows that unemployment caused by a demand shortage persistently occurs on the unique dynamic equilibrium path. Finally, section 5 summarizes the implication of this paper.

\section{An Economy with Capital Accumulation}

As a benchmark I first examine an economy in which status preference directed toward real capital creates long-run growth, such as presented by Corneo and Jeanne (1995). In a one-commodity economy firms are assumed to input labor $l$ and capital $k$ to produce $y$ using the following linear homogeneous production function: 


$$
\begin{aligned}
y & =F(l, k)=f(n) k, \quad \text { where } n=l / k, \\
f(n)>0, \quad f^{\prime}(n) & <0, \quad f(0)=0, \quad f(\infty)=\infty, \quad f(0)=\infty, \quad f(\infty)=0 .
\end{aligned}
$$

Without adjustment costs of investment, the optimal conditions are

$$
\omega=f(n), \quad r=f(n)-f(n) n,
$$

where $\omega$ is the real wage. Needless to say, the maximized firm value is $k$ in this setting.

A representative household holds wealth $a$ and earns interest $r a$ and wage $\omega$, where his (or her) labor endowment is normalized to unity. The flow budget equation is

$$
\dot{a}=r a+\omega-c .
$$

The household's utility is assumed to depend on consumption $c$ and relative social status $a-a^{*}$ where $a^{*}$ is the social average of wealth holding. ${ }^{\square}$ Let $\rho$ the subjective discount rate, the utility is given by

$$
\begin{gathered}
U=\int_{0}^{\infty}\left(u(c)+w\left(a-a^{*}\right)\right) \exp (-\rho t) d t \\
u^{\prime}(.)>0, \quad u^{\prime \prime}(.)<0, \quad u^{\prime}(0)=\infty ; \quad w^{\prime}(.)>0, \quad w^{\prime \prime}(.)<0 .
\end{gathered}
$$

The household maximizes $U$ subject to (3), and then the optimal conditions are

$$
\begin{gathered}
u^{\prime}(c)=\lambda, \\
\dot{\lambda} / \lambda=\rho-r-w^{\prime}\left(a-a^{*}\right),
\end{gathered}
$$

where $\lambda$ is the co-state variable of $k$. The transversality condition is

$$
\lim _{t \rightarrow \infty} \lambda_{t} a_{t} \exp (-\rho t)=0 .
$$

Since social average wealth $a^{*}$ always equals individual wealth holding $a$, at any point in time

$$
w^{\prime}\left(a-a^{*}\right)=w^{\prime}(0)>0 .
$$

This implies the statement of Keynes shown at the outset of the introduction: the needs which satisfy the desire for superiority are insatiable since the social average wealth and each household's wealth increase in parallel. Therefore, from (5) and (6),

$$
\begin{gathered}
\eta(c)\left(\frac{\dot{c}}{c}\right)=r+w^{\prime}(0) / u^{\prime}(c)-\rho, \\
\text { where } \eta(c)=-u^{\prime \prime}(c) c / u^{\prime}(c) .
\end{gathered}
$$

\footnotetext{
${ }^{1}$ See also the first model of Clark and Oswald (1998) and model 3 of Bakshi and Chen (1996) for this setting of status preference.
} 
The market equilibrium conditions are

$$
\begin{array}{ll}
\text { the commodity market: } & f(n) k=c+\dot{k}, \\
\text { the labor market: } & n k(=l)=1, \\
\text { the asset market: } & a=k .
\end{array}
$$

Using (2), (8), (9) and (10),

$$
\begin{gathered}
\eta(c)\left(\frac{\dot{c}}{c}\right)=f(1 / k)-f(1 / k)(1 / k)+w^{\prime}(0) / u^{\prime}(c)-\rho, \\
\dot{k}=f(1 / k) k-c,
\end{gathered}
$$

which formulate an autonomous dynamic system with respect to $c$ and $k$. Figure 1 illustrates the boundary curves of (12) and (13) in the case where the two curves intersect whereas figure 2 does so in the case where they do not.

As shown in figure 1, there are two intersection points $k_{1}$ and $k_{2}$ if the two curves intersect. They satisfy

$$
\begin{gathered}
\rho=f(1 / k)-f(1 / k)(1 / k)+w^{\prime}(0) / u^{\prime}(c), \\
c=f(1 / k) k .
\end{gathered}
$$

If the initial level of $k$ is smaller than $k_{2}$, the economy approaches $\mathrm{A}$ and hence $\mathrm{k}$ eventually becomes $k_{1}$ on the dynamic equilibrium path.

Without status preference, the steady state level of $k$ is $k_{0}$ that satisfies

$$
\rho=f\left(1 / k_{0}\right)-f\left(1 / k_{0}\right)\left(1 / k_{0}\right)
$$

instead of (14). This is the steady-state level of $k$ in the standard neoclassical growth model. In figure $1 k_{0}$ is given by the intersection point of the $\dot{c}=0$ curve and the $k$ axis. Note that $k_{1}$ is higher than $k_{0}-$ i.e., status preference raises the steady state level of $k$.

If the initial level of $k$ is higher than $k_{2}$, the path along $\mathrm{BD}$ is the unique equilibrium path. ${ }^{2}$ Note that on $\mathrm{BD} k$ diverges to infinity and yet the transversality condition is satisfied. In fact, from (13), along BD

$$
\lim _{k \rightarrow \infty} \dot{k} / k=\lim _{k \rightarrow \infty} f(1 / k)-c / k=0,
$$

and $\lambda\left(=u^{\prime}(c)\right)$ is finite since $c$ stays to be finite:

$$
c=u^{\prime-1}\left(w^{\prime}(0) / \rho\right) \text {. }
$$

\footnotetext{
${ }^{2}$ As proven in the appendix all the other paths cannot be dynamic equilibrium paths.
} 
Therefore, from (11) transversality condition (7) is valid.

When status preference $w^{\prime}(0)$ is large enough, the two boundary curves do not intersect. This case is illustrated in figure 2. Along the dynamic equilibrium path $k$ always diverges to infinity while $c$ increasingly approaches $u^{\prime-1}\left(w^{\prime}(0) / \rho\right)$, regardless of the initial capital level. The transversality condition is proven to be valid in the same way as above.

\section{A Monetary Economy}

In the capitalist-spirit economy capital eternally grows although consumption stays below a finite level. Extra commodity production is all invested in capital. People's demand for capital does not disappear since the social average of wealth rises together with the representative household's wealth and hence the representative household is never satiated with capital accumulation. This is quite in conformity with the spirit of capitalism à la Max Weber (1958).

Whether capital is accumulated in order to receive its returns or to satisfy status preference, commodity demand (for the purpose of investment) is created and hence labor demand also is. However, if status preference is directed toward an unproducible asset, such as money and land, the commodity demand decreases. Therefore deflation or a shortage of demand, causing persistent unemployment, may occur.

This section considers a pure monetary economy in which people accumulate money to satisfy status preference, and explores the possibility of persistent deflation. It also applies the same argument to the case where status preference is directed toward land. In the latter case persistent land-price inflation obtains. The possibility of a persistent shortage of demand is examined in the next section.

In the present monetary economy firms are assumed to produce output $y$ by using only labor $l$ with a constant-returns-to-scale technology:

$$
y=\theta l,
$$

where input-output ratio $\theta$ is constant. Therefore, given real wage $\omega$, the firm sector's demand for labor $l$ satisfies 


$$
\begin{gathered}
l=0 \quad \text { if } \quad \omega>\theta, \\
0<l<\infty \quad \text { if } \quad \omega=\theta, \\
l=\infty \quad \text { if } \quad \omega<\theta .
\end{gathered}
$$

Because of technology (16) the firm value is zero and thus money is a sole asset in this economy. The representative household's labor endowment is again assumed to be 1 , but in order to take into account the possibility of unemployment its actual labor supply is denoted $x$, where

$$
x=\min (1, l) .
$$

Since full employment is assumed to hold in this section, $x$ equals 1 .

Subject to the flow budget equation:

$$
\dot{m}=\omega x-c-\pi m,
$$

where $\pi$ is the inflation rate of nominal commodity price $P$, the household maximizes its utility:

$$
\begin{gathered}
U=\int_{0}^{\infty}\left(u(c)+w\left(a-a^{*}\right)+v(m)\right) \exp (-\rho t) d t, \\
v^{\prime}(m)>0, \quad v^{\prime \prime}(m)<0, \quad v^{\prime}(0)=\infty, \quad v^{\prime}(\infty)=0, \quad \lim _{m \rightarrow \infty} v^{\prime}(m) m>0,
\end{gathered}
$$

where $m$ represents real money balances and $v(m)$ is liquidity preference for the transaction motive. ${ }^{\text {B }}$ Status preference is represented by $w\left(a-a^{*}\right)$, as in the previous model. In the present setting individual total wealth $a$ equals real balance $m$.

$$
a=m
$$

People hold money for both the status and transaction motives.

The optimal conditions of this problem are

$$
\begin{gathered}
u^{\prime}(c)=\lambda, \\
\dot{\lambda} / \lambda=\rho+\pi-\left[w^{\prime}\left(a-a^{*}\right)+v^{\prime}(m)\right] .
\end{gathered}
$$

Since $a^{*}$ always equals $a$, as mentioned in the capitalist-spirit model, these conditions yield

$$
\rho+\eta(c)\left(\frac{\dot{c}}{c}\right)+\pi=\left[w^{\prime}(0)+v^{\prime}(m)\right] / u^{\prime}(c) .
$$

\footnotetext{
${ }^{3}$ Feenstra (1986) proves that a cash-in-advance model can equivalently be replaced by a money-in-utility model. The last property in (19) is imposed so that a hyper-inflation path is avoided. See Blanchard and Fischer (1989, p.241) for this property.
} 
The transversality condition is the same as (7).

Market equilibrium conditions are

$$
\begin{array}{ll}
\text { the money market: } & M / P=m, \\
\text { the commodity market: } & \theta x=c, \\
\text { the labor market: } & l=1,
\end{array}
$$

where $M$ is the nominal money stock. From (18), (24) and (25),

$$
c=\theta .
$$

From (22) and (26), $m$ satisfies

$$
\dot{m} / m(=-\pi)=\rho-\left[w^{\prime}(0)+v^{\prime}(m)\right] / u^{\prime}(\theta) .
$$

Figure 3 illustrates this dynamics in the case where status preference $w^{\prime}(0)$ or production capacity $\theta$ is so low that

$$
\rho>w^{\prime}(0) / u^{\prime}(\theta) .
$$

In this case the path along which $P$ jumps to the level that makes $m$ equal $m^{*}$, where $m^{*}$ satisfies

$$
\left[w^{\prime}(0)+v^{\prime}\left(m^{*}\right)\right] / u^{\prime}(\theta)=\rho,
$$

and thereafter stays is an equilibrium path.

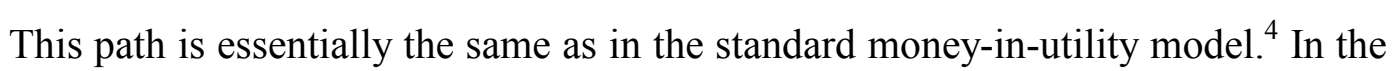
presence of status preference $w^{\prime}(0)$, however, this is not the sole equilibrium path. All the hyper-deflationary paths along $\mathrm{AB}$ in figure 3 are also equilibrium paths. In fact, from (19), (20) and (27), on these paths

$$
\lim _{t \rightarrow \infty} \dot{a} / a=\lim _{t \rightarrow \infty} \dot{m} / m=\rho-w^{\prime}(0) / u^{\prime}(\theta)<\rho,
$$

which implies the validity of transversality condition (7). Thus, this economy is most probably located in a state with persistent deflation.

In the case where status preference $w^{\prime}(0)$ or production capacity $\theta$ is so high that

$$
\rho<w^{\prime}(0) / u^{\prime}(\theta)
$$

instead of (28), $\dot{m} / m$ given by (27) is always negative. It is well known that these paths of $m$ are all infeasible under the last property of (19) since $m$ becomes negative within a finite time. ${ }^{\mathrm{B}}$ Therefore, there is no equilibrium path under (30).

\footnotetext{
${ }^{4}$ See e.g. Blanchard and Fischer (1989, pp.239-245) for this model.

${ }^{5}$ See Blanchard and Fischer (1989, p.241-242) for the proof of this property.
} 
Note that the same argument applies to the case where land is the object of status preference if nominal commodity price $P$ is taken as the relative commodity price compared to the land price and money supply $M$ as land endowment. In this economy people prefer not the land size but the land value for the purpose of achieving social status. Since the land price is given by $1 / P$ in this case, the hyper-deflationary paths are taken as those on which the land price keeps expanding while consumption remains to be constant. As the status preference directed toward land increases, any price path cannot be an equilibrium path.

The discussion of the present section may remind us of the Japanese land-price hyperinflation and crash. In the late 1980s Japanese land prices were pushed up by people's status preference, and eventually they attained the level equivalent to the price of the whole U.S. territory or even double. As the status preference escalated more, the equilibrium path was lost and eventually land prices crashed in the early 1990s. Then, the object of people's status preference converted to money, and thereafter long-run deflation has been occurring.

\section{A Monetary Economy with Nominal Wage Sluggishness}

In the previous section it is shown that there is no equilibrium path under (30) i.e., the case where status preference $w^{\prime}(0)$ is so high that if consumption $c$ takes the full employment level $\theta$, a wealth-holding desire exceeds a desire for consumption, the latter of which is $\rho$ when $P$ stays constant. Thus, $P$ has to keep moving so that an equilibrium path would be realized. As shown in the previous section, however, any price movement cannot realize an equilibrium path. In such a case a shortage of effective demand and unemployment may naturally occur as steady-state phenomena once nominal wage adjustment is sluggish. ${ }^{\mathrm{B}}$ This section is devoted to proving this property.

It may be noteworthy that in a standard money-in-utility model without status preference full employment is eventually reached even under nominal wage

\footnotetext{
${ }^{6}$ If perfect nominal wage adjustment is assumed, any labor demand shortage at any point in time is 'by definition' avoided.
} 
sluggishness. In the presence of status preference, however, full employment is never reached, as shown below. Unemployment occurs as a steady-state phenomenon.

To represent sluggish adjustment of nominal wage $W$, a new Keynesian Phillips curve with the following functional form:

$$
\dot{W} / W=\alpha(l-1),
$$

is assumed, where the full employment level is normalized to unity. The commodity and money markets are assumed to adjust perfectly, as in (23) and (24). From (17), if $W / P>$ $\theta$, labor demand $l$ is zero and therefore commodity supply is zero, which immediately makes $P$ jump upward so that $W / P=\theta$. If $W / P<\theta$, then from (17) $l$ is $\infty$ and hence even under the sluggish money wage adjustment given by (31) $W$ instantaneously rises to $\theta P$. Thus, it is always satisfied that

$$
W / P=\omega=\theta,
$$

from which

$$
\dot{W} / W=\pi .
$$

Since (32) is valid, from (17) $l$ can take any value. Then, $l$ is determined by effective demand $x(=c / \theta$ from (24)).

$$
l=c / \theta
$$

From this property, (31) and (33), the dynamics of $P$ is

$$
\pi=\alpha(c / \theta-1),
$$

which implies that $P$ and $W$ move in parallel in accordance with the gap between production capacity $\theta$ and effective demand $c .8$ From (22), (23) and (34),

$$
\begin{gathered}
\dot{m} / m(=-\pi)=-\alpha(c / \theta-1), \\
\eta(c)\left(\frac{\dot{c}}{c}\right)=\left[w^{\prime}(0)+v^{\prime}(m)\right] / u^{\prime}(c)-\alpha(c / \theta-1)-\rho .
\end{gathered}
$$

(35) and (36) formulate an autonomous dynamic system with respect to $m$ and $c .9$

\footnotetext{
${ }^{7}$ See Roberts (1995) for discussions on various models of such sluggish price/wage adjustment, called new Keynesian Phillips curves.

${ }^{8}$ Note that this equation is valid only when $c / \theta \leq 1$. If $c / \theta>1$, demand exceeds supply in the commodity market since the maximum commodity supply is $\theta$, and because of the instantaneous adjustment of the commodity market $P$ immediately jumps upward so that $c / \theta=1$. Thus, the following dynamics is valid only in the case where $c / \theta \leq 1$.

${ }^{9}$ This dynamics is similar to that in Ono $(1994,2001)$. In the present model status preference $w\left(a-a^{*}\right)$ and nominal wage sluggishness cause persistent unemployment while in Ono insatiable liquidity preference $\left(v^{\prime}(\infty)>0\right)$ and
} 
As long as full employment eventually obtains, the steady state is essentially the same as that in the standard money-in-utility model. In fact, from (35) and (36), the steady-state levels of $c$ and $m$ are the same as those in (26) and (29), viz. those under perfect nominal wage adjustment. However, in the previous section it has already been shown that this state does not exist under (30).

In this case a shortage of effective demand occurs $(c<\theta)$, and thus from (35) $m$ diverges to infinity, causing $v^{\prime}(m)$ to be zero. In this state, from (36), $c$ satisfies

$$
w^{\prime}(0) / u^{\prime}(c)=\rho+\alpha(c / \theta-1) .
$$

In figure 4 , the $\ell$ and $\pi$ curves respectively stand for the left- and right-hand sides of (37) and $c_{u}$ is the level that satisfies (37). Under (30) the $\ell$ curve is located above the $\pi$ curve when $c=\theta$. Thus, in order for $c_{u}$ to be positive the $\pi$ curve must be located above the $\ell$ curve when $c=0$. This condition is valid when nominal wage adjustment speed $\alpha$ must be sluggish enough to satisfy

$$
\rho>\alpha .
$$

Figure 5 illustrates the dynamics of (35) and (36) under conditions (30) and (38). There is a unique equilibrium path represented by $\mathrm{AB}$. Along this path $m$ diverges to infinity, causing $v^{\prime}(m)$ to be zero, and from (36) $c$ asymptotically approaches $c_{u}$ that satisfies (37). Thus, $c$ remains to be smaller than $\theta$, causing unemployment to last forever. In this state $P$ continues to decline and $m$ (=a from (20)) expands to infinity, and yet the transversality condition is valid. In fact, from (35) and (36), along this path

$$
\lim _{t \rightarrow \infty} \dot{a} / a=\rho-w^{\prime}(0) / u^{\prime}\left(c_{u}\right)<\rho,
$$

which implies the validity of transversality condition (7). Any other path is either infeasible or inconsistent with the transversality condition, as proven in the same way as in the case of figure 2 .

It may be interesting to compare figure 5 with figure 2 . They have quite similar structures to each other, and yet their implications are quite opposite. The status preference toward real capital leads to persistent growth while that toward money results in persistent stagnation.

nominal price sluggishness lead to persistent excess supply. 
Note that conventional Keynesian models need either nominal or real wage rigidity when explaining persistent unemployment whereas neither of them is necessary in the present status-preference model. In fact, in the steady state $P$ and $W$ continue to adjust and realize full-employment real wage $\theta$, and yet consumption $c$ stays below $c_{u}$, causing persistent unemployment to occur.

The steady state obtained above has Keynesian features. For example, an increase in fiscal spending raises consumption. Specifically, in the presence of fiscal spending $g$, the commodity market equilibrium condition (24) is replaced by

$$
\theta x=c+g,
$$

and then (37) is revised to

$$
w^{\prime}(0) / u^{\prime}(c)=\rho+\alpha((c+g) / \theta-1) .
$$

Thus, an increase in $g$ shifts the $\pi$ curve upward in figure 4 , causing intersection point $\mathrm{A}$ to move rightward on the $\ell$ curve and hence $c_{u}$ to increase.

Also, from the right-hand side of (39), a rise in nominal wage adjustment speed $\alpha$ turns the $\pi$ curve counterclockwise around B with the $\ell$ curve unaffected. Consequently, intersection point A moves leftward on the $\ell$ curve and hence $c_{u}$ declines. This result is quite opposite to the conventional view shared by both neoclassical and Keynesian economics -i.e., the more rapidly prices and wages adjust, the sooner an effective demand shortage disappears. It is consistent with Keynes's own view (1936, Ch.19) -i.e., a rise in the wage adjustment speed reduces effective demand.

\section{Conclusion}

In the presence of status preference people attempt to accumulate more wealth than others. As the economy grows, each individual accumulates wealth, but the social average also rises and hence his (or her) desire for wealth accumulation remains to have the same magnitude.

If such status preference is directed toward an asset that can be produced (viz. real capital), it keeps generating new employment and expanding production, but consumption does not increase. Extra products are all invested in capital formation in 
order to satisfy status preference, and therefore the economy eternally grows. This is quite in conformity with Max Weber's capitalist-spirit economy.

If the status preference is directed toward an asset that cannot be produced, such as money and land, however, it does not create any commodity demand. People attempt to accumulate money or land by restricting consumption. In the case where land is the object of status preference, the commodity price compared to the land price continues to decline, that is, land-price inflation occurs. In the case where money is the object, commodity-price deflation occurs. In any case a decline in the relative commodity price enables people to increase the real value of wealth.

As this status preference increases, an equilibrium price path disappears. In this case, if nominal wage adjustment is sluggish, as given by a new Keynesian Phillips curve, a shortage of effective demand naturally occurs. There is a unique dynamic equilibrium path along which unemployment persistently occurs.

It is contrasting to the standard money-in-utility model without status preference. Without status preference full employment is eventually reached even under nominal wage sluggishness. In the presence of status preference, however, full employment is never reached although wages continue to adjust. The steady state is characterized by a Keynesian shortage of demand.

To summarize, whether status preference is directed toward a producible asset or an unproducible one leads to a completely opposite performance of an economy. If it is directed toward a producible asset (viz. real capital), an economy eternally grows. If it is toward an unproducible one (viz. money), an economy suffers persistent unemployment and deflation.

\section{Appendix}

From (5), (12) and (13),

$$
\dot{\lambda} / \lambda+\dot{k} / k=-c / k+f(1 / k)(1 / k)-w^{\prime}(0) / u^{\prime}(c)+\rho,
$$

From (1), (4) and (A1), on any path along which $c$ converges to zero and $k$ diverges to infinity, 


$$
\lim _{t \rightarrow \infty} \dot{\lambda} / \lambda+\dot{k} / k=\rho,
$$

which implies the invalidity of transversality condition (7).

On any path along which $c$ increases and $k$ decreases, $\dot{k}$ given by (13) is strictly negative when $k$ is zero. Since $k$ cannot be negative, this path is infeasible. 


\section{References}

Bakshi, Gurdip S., and Zhiwu Chen (1996), "The Spirit of Capitalism and Stock-Market Prices," American Economic Review, vol.86, March 1996, pp.133-157.

Blanchard, Olivier J., and Stanley Fischer, Lectures on Macroeconomics, Cambridge, Mass.: MIT Press, 1989.

Carroll, Christopher D., "Why do the Rich Save So Much?" in Does Atlas Shrug? edited by Joel B. Slemrod, Cambridge, Mass.: Harvard University Press, 2000, pp.465-489.

Clark, Andrew E., and Andrew J. Oswald, "Comparison-Concave Utility and Following Behaviour in Social and Economic Settings," Journal of Public Economics, vol.70, 1998, pp.133-155.

Cole, Harold L., George J. Mailath, and Andrew Postlewaite, "Social Norms, Savings Behavior, and Growth,” Journal of Political Economy, vol.100, December 1992, pp.1092-1125.

Corneo, Giacomo, and Olivier Jeanne, "Status-Seeking Can Generate Long-Run Growth in the Solow-Cass Model," Discussion Paper No.A-497, University of Bonn, 1995.

Corneo, Giacomo, and Olivier Jeanne, "On Relative Wealth Effects and the Optimality of Growth,” Economics Letters, vol.54, January 1997, pp.87-92.

Corneo, Giacomo, and Olivier Jeanne, "Social Organization in an Endogenous Growth Model,” International Economic Review, vol.40, August 1999, pp.711-726.

Feenstra, Robert C., "Functional Equivalence between Liquidity Costs and the Utility of Money," Journal of Monetary Economics, vol.17, March 1986, pp.271-291.

Fershtman, Chaim, Melvin M. Murphy, and Yoram Weiss, "Social Status, Education, and Growth," Journal of Political Economy, vol.104, February 1996, pp.108-132.

Futagami, Koichi, and Akihisa Shibata, "Keeping One Step Ahead of the Joneses: Status, the Distribution of Wealth, and Long Run Growth," Journal of Economic Behavior and Organization, vol.36, July 1998, pp.109-126.

Keynes, John M., The General Theory of Employment, Interest, and Money, London: Macmillan, 1936.

Keynes, John M., "Economic Possibilities for Our Grandchildren," in Essays in Persuasion, The Collected Writings of John Maynard Keynes, vol. IX, London: Macmillan, 1972, pp.321-332. Originally published in 1930.

Ono, Yoshiyasu, Money, Interest, and Stagnation, Oxford University Press, 1994.

Ono, Yoshiyasu, "A Reinterpretation of Chapter 17 of Keynes's General Theory: Effective Demand Shortage Under Dynamic Optimization," International Economic Review, vol.42, February 2001, forthcoming. 
Rauscher, Michael, "Conspicuous Consumption, Economic Growth, and Taxation" Journal of Economics, No.1, vol.66, 1997, pp.35-42.

Roberts, John M., "New Keynesian Economics and the Phillips Curve," Journal of Money, Credit, and Banking, vol.27, November 1995, pp.975-984.

Veblen, Thorstein, The Theory of the Leisure Class, London: George Allen and Unwin, 1949. Originally published by New York: Macmillan, 1899.

Weber, Max M., The Protestant Ethic and the Spirit of Capitalism, New York: Charles Scribner's Sons, 1958.

Zou, Hen-fu, "The Spirit of Capitalism and Long-Run Growth," European Journal of Political Economy, vol.10, July 1994, pp.279-293.

Zou, Hen-fu, "The Spirit of Capitalism and Savings Behavior," Journal of Economic Behavior and Organization, vol.28, September 1995, pp.131-143.

Zou, Hen-fu, "The Spirit of Capitalism, Social Status, Money, and Accumulation," Journal of Economics, No.3, vol.68, 1998, pp.219-233. 


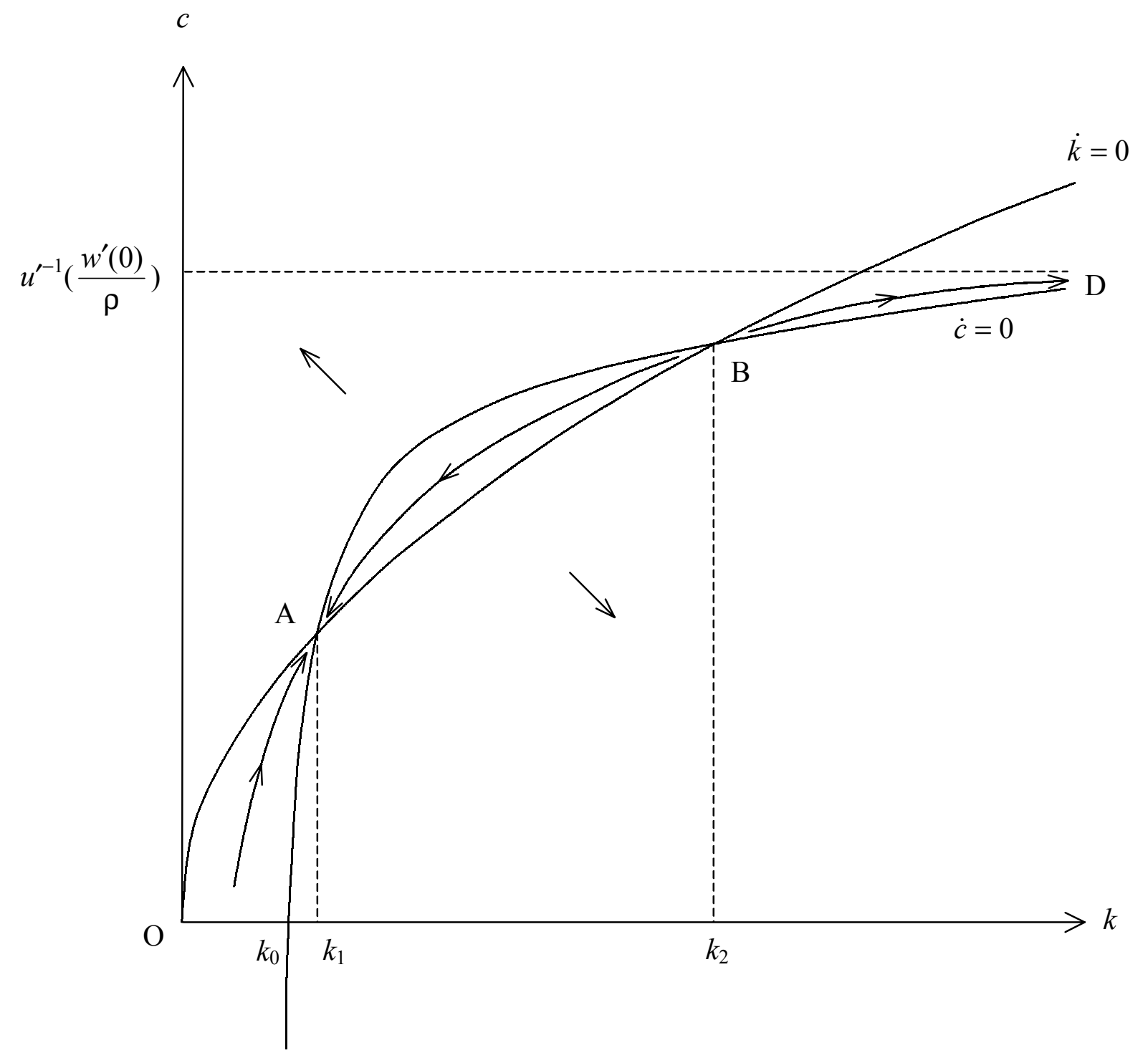

Figure 1 


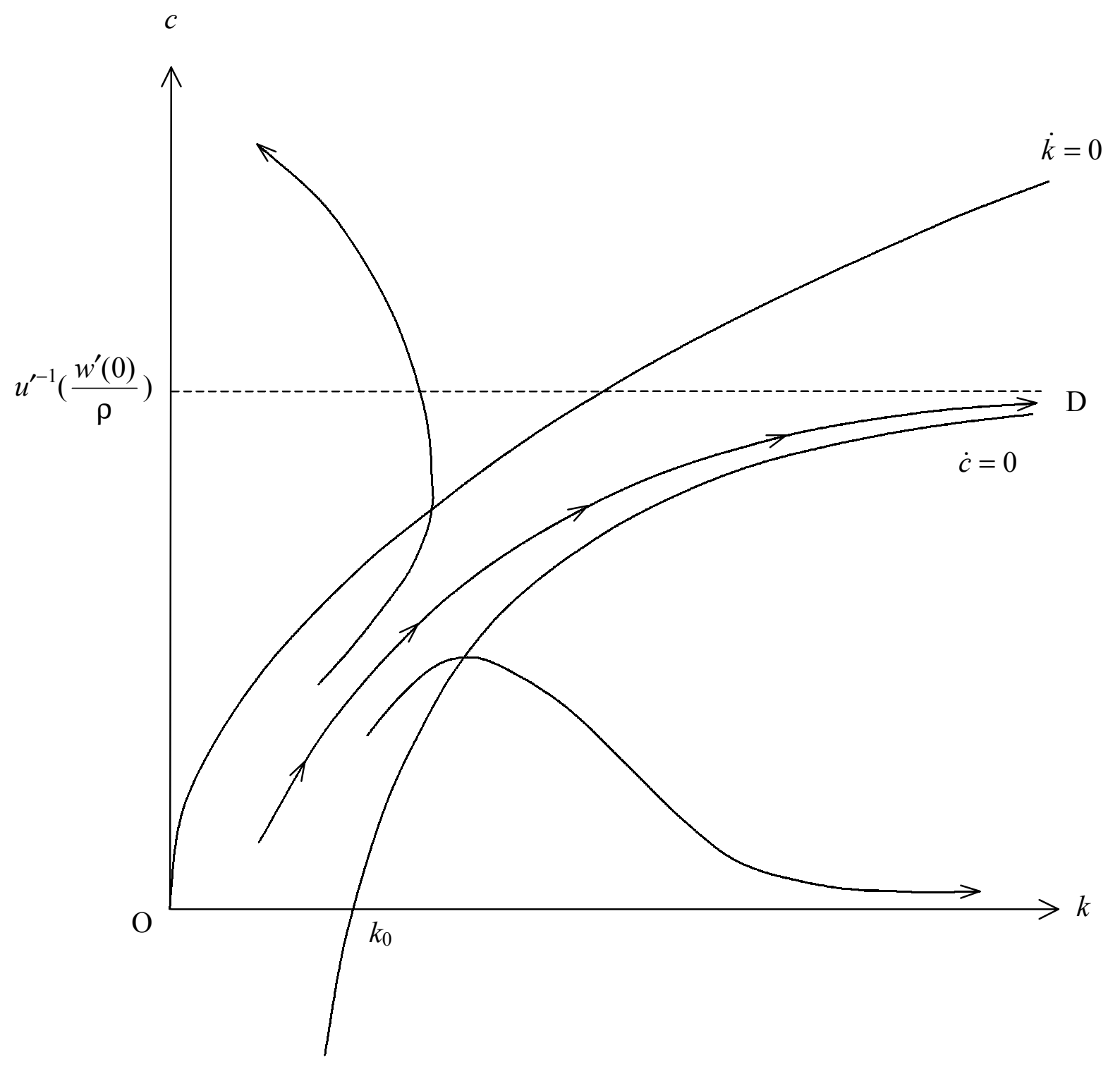

Figure 2 




Figure 3 


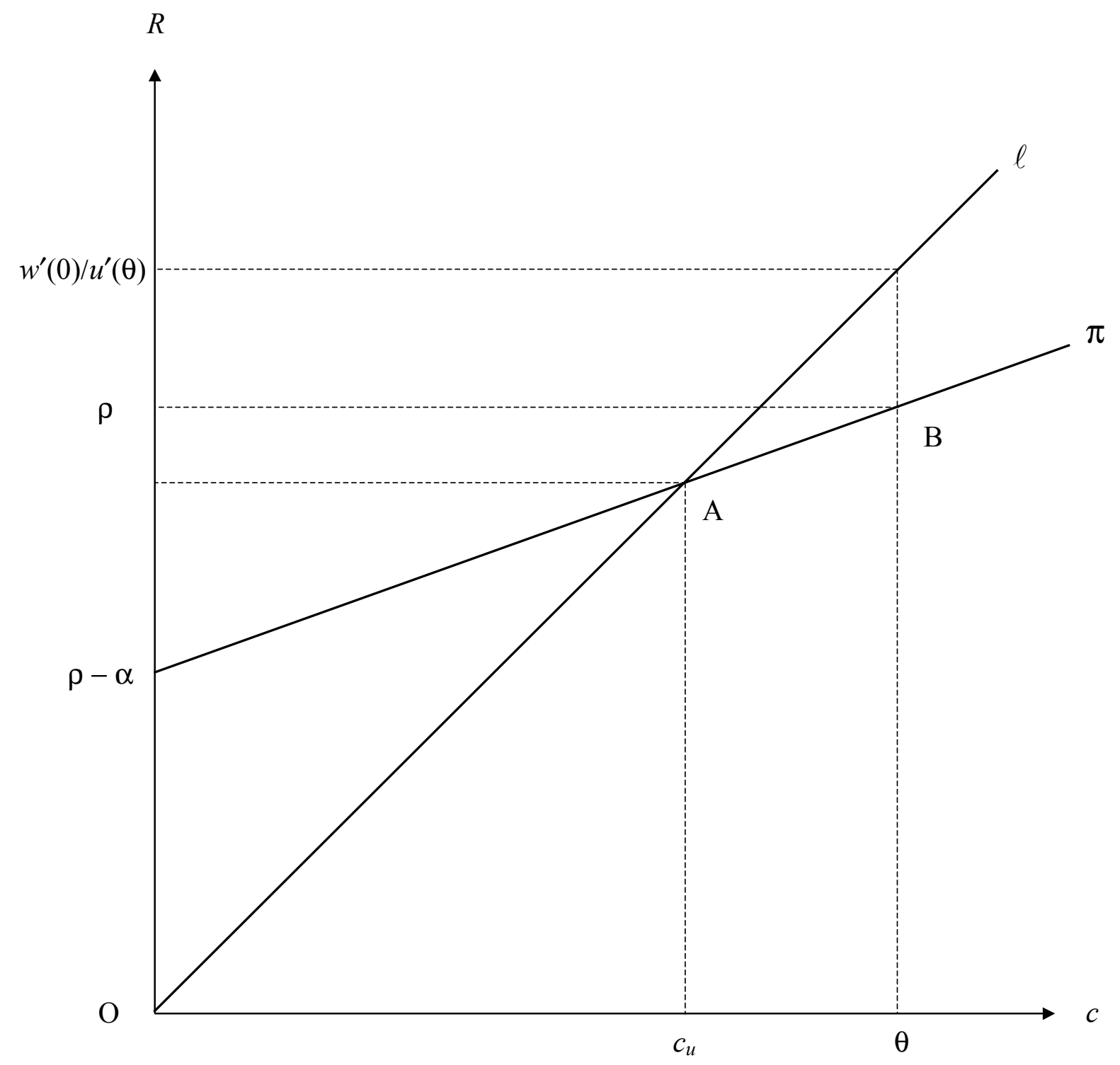

Figure 4 


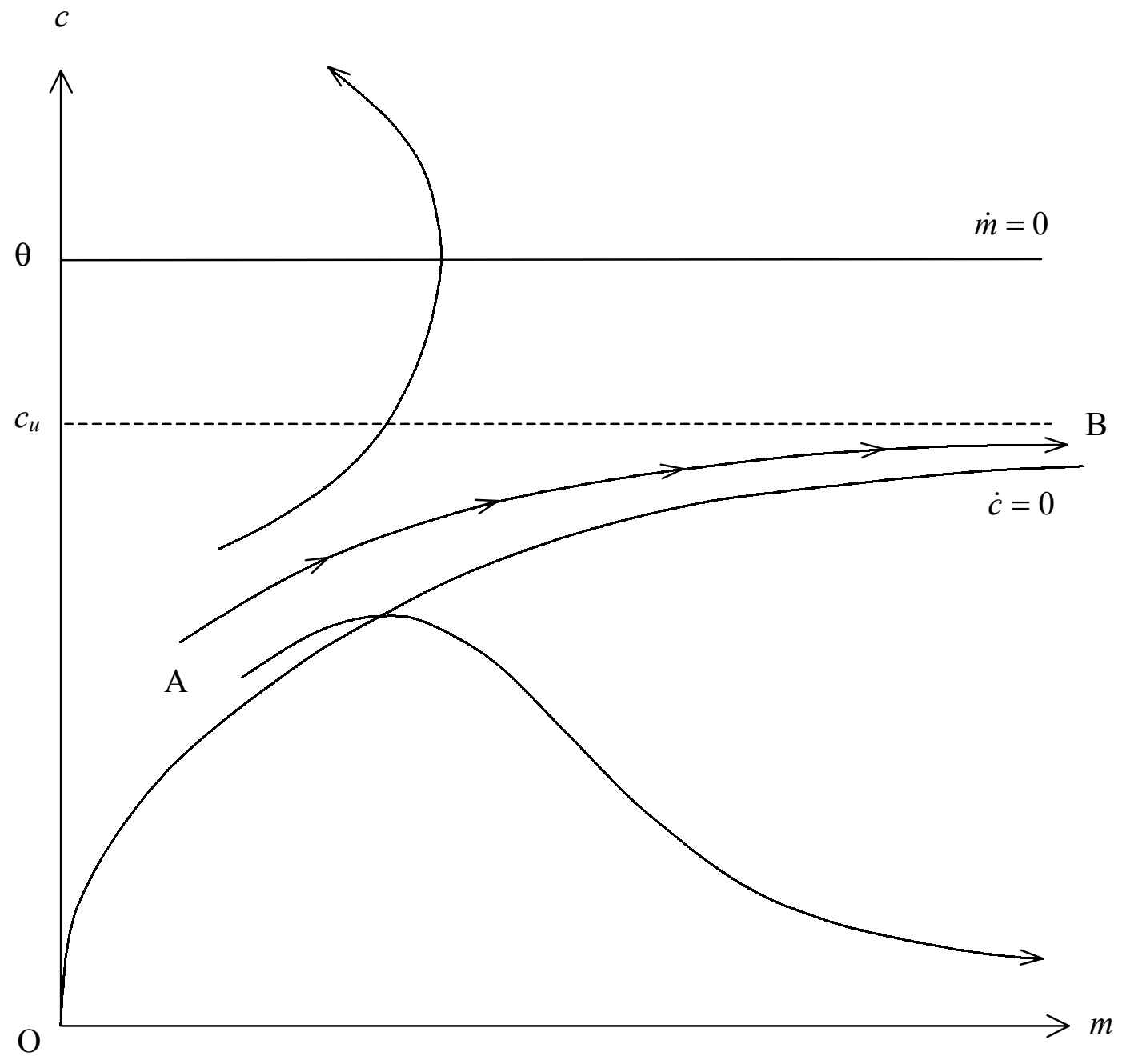

Figure 5 